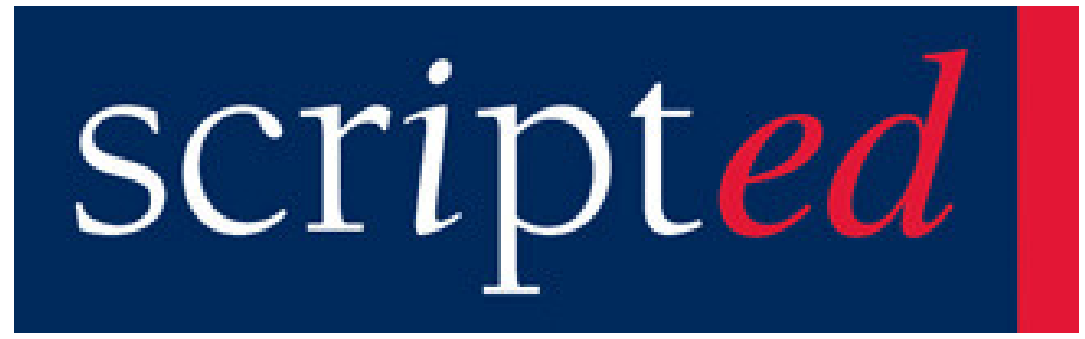

Volume 4, Issue 4, September 2007

\title{
Net Neutrality and Consumer Access to Content
}

\author{
Christopher T Marsden*
}

\begin{abstract}
'Net Neutrality' is a very heated and contested United States policy principle regarding access for content providers to the Internet end-user, and potential discrimination in that access where the end-user's ISP (or another ISP) blocks that access in part or whole. The suggestion is that the problem can be resolved by either introducing greater competition, as for instance in certain Western European nations under the Telecoms Framework 2002 (as proposed for amendment 2007), or closely policing conditions for vertically integrated service, such as VOIP. This assumes that competition in the 'local loop' or 'last mile' to the end-user subscriber provides a choice of platform, and therefore rigorous telecoms competition regulation resolves the issue in Europe. However, that may not be the whole story. The question this paper aims to answer is: Are Internet Service Providers motivated to require content providers to pay for superior service via lower levels of service for the same price (e.g. blocking or "throttling" content) or higher price for higher Quality of Service? Can abusive discrimination take place even where an ISP does not have dominance? I
\end{abstract}

\footnotetext{
* Christopher T Marsden is Lecturer in Law and 2007-8 Director, LL.M. Programme on Information Technology, Media and Entertainment Law, University of Essex, Wivenhoe Park, Colchester. Comments welcome at: ctmarsden@yahoo.co.uk. The author is grateful for advice and discussions with Rudolf van der Berg, Jonathan Cave, Marvin Sirbu, Jon Crowcroft, Dave Clark, Mark Handley, Ian Brown, Kevin Werbach, Tim Wu, Larry Lessig, Mark Lemley, David McGowan, Alex Wolfson, Lilian Edwards, Eli Noam, Tom Aust, Jonathan Aronson, Richard Cawley, Martin Cave, Tom Kiedrowski, Herbert Ungerer, Jonathan Zittrain, and participants at the various conferences named in this article, the TPRC conferences 2005-7, the Wharton Media Law Symposia 2005-7, and HarvardSwiss Re Ruschlikon conferences in that same period. All errors and omissions remain my own.
} 
consider market developments and policy responses in Europe and the United States, conclusions and regulatory recommendations.

DOI: $10.2966 /$ scrip.040407.407

\footnotetext{
(c)

(C) Christopher T Marsden 2007. This work is licensed under a Creative Commons Licence. Please click on the link to read the terms and conditions.
} 


\section{Introduction}

'Net Neutrality' is a very heated and contested United States policy principle regarding access for content providers to the Internet end-user, and potential discrimination in that access where the end-user's ISP (or another ISP) blocks that access in part or whole. ${ }^{1}$ Net neutrality has been variously defined, most prominently by regard to its forerunner "open access" by legal theorists Lemley and Lessig, ${ }^{2}$ and the term 'Network Neutrality' was first used by $\mathrm{Wu}^{3}$ However, net neutrality's definition is contested and I unpack the definition in the following section. The suggestion is that the problem can be resolved by either introducing greater competition, as for instance in certain Western European nations under the Telecoms Framework $2002^{4}$ (as proposed for amendment 2007), or closely policing conditions for vertically integrated service, such as VOIP.

This assumes that competition in the 'local loop' or 'last mile' to the end-user subscriber provides a choice of platform, and therefore rigorous telecoms competition regulation resolves the issue in Europe. However, that may not be the whole story. The question this paper aims to answer is: Are Internet Service Providers (ISPs) motivated to require content providers to pay for superior service via lower levels of service for the same price (e.g. blocking or "throttling" content) or higher price for higher Quality of Service (QoS)? Can abusive discrimination take place even where an ISP does not have dominance? I consider market developments and policy responses in Europe and the United States, conclusions and regulatory recommendations. By 'Internet content', I refer to content accessible to the general consumer on the public Internet, ${ }^{5}$ as opposed to secure private networks. ${ }^{6}$

To reiterate the standard analysis, abusive discrimination in access to networks is usually characterised in telecoms as a monopoly problem, manifested where one or two ISPs have dominance typically in the "last mile" of access for end-users. The classic regulatory action to prevent blocking of access was the decision, by the US Federal Communications Commission (FCC), to enforce non-discrimination against a small ISP that had been blocking Voice over Internet Protocol (VOIP) service (Madison River Communications). ${ }^{7}$ ISPs can discriminate against all content, or

\footnotetext{
${ }^{1}$ Often subject to special conditions (financial recompense or other types of payment).

${ }^{2}$ M A Lemley and L Lessig "The End of End-to-End: Preserving the Architecture of the Internet in the Broadband Era" (2001) 48 University of California at Los Angles Law Review, 925.

${ }^{3}$ T Wu (2003) "Network Neutrality and Broadband Discrimination" (2003) 2 Journal of Telecommunications and High Technology Law, at 141.

${ }^{4}$ The telecoms framework consists of five Directives, implemented in Member States in 2003, and reviewed on a process that began in 2006 and may conclude in 2008: see http://ec.europa.eu/information_society/policy/ecomm/tomorrow/roadmap/index_en.htm

${ }^{5}$ See K L Trope, "Voice Over Internet Protocol: The Revolution in America's Telecommunications Infrastructure" (2005) 22(1) 12 Computers \& Internet Law, 1,4. for definitions.

${ }^{6}$ See OECD (2006) "Next Generation Networks: Evolution and Policy Considerations", 3 October 2006 at http://www.oecd.org/document/12/0,2340,en_2649_34223_37392780_1_1_1_1,00.html

${ }^{7}$ Madison River Communications, LLC, Order, DA 05-543, 20 FCC Rcd 4295 (2005), available at: http://hraunfoss.fcc.gov/edocs_public/attachmatch/DA-05-543A1.pdf
} 
against the particular content that they compete with, where they are vertically integrated. Hahn and Wallsten explain:

"net neutrality has no widely accepted precise definition, but usually means that broadband service providers charge consumers only once for Internet access, don't favor one content provider over another, and don't charge content providers for sending information over broadband lines to end users." 8

Frieden, whose perspective is analytical and consumer-centric, reflects where regulators' perspectives need by law to be focused. ${ }^{9}$ He summarises:

"Network neutrality advocates worry that major ISPs have both the wherewithal and incentive to bifurcate the Internet into one medium increasingly prone to congestion and declining reliability and one offering superior performance and potential competitive advantages to users able and willing to pay, or affiliated with an ISP operating a major bitstream transmission network".

I agree that this is the focus of the problem: network owners with vertical integration into content or alliances have enhanced incentives to require content owners (who may also be consumers) to pay a toll to use the higher speed networks that they offer to end-users. In European debate, the issue has been dismissed by many as an "American problem" caused by the abandonment of Local Loop Unbundling (LLU) regulation for broadband competition in the local access network. The European Commission has proposed a more sophisticated approach in its review of the Regulatory Framework, adding interoperability and minimal service quality requirements to the interconnection requirements. ${ }^{10}$ The i2010 High Level Group stated:

"The 'net neutrality' debate in the USA highlights operators' propensity to enter into preferential distribution arrangements with some content providers... [this] may be problematic and the issue needs to be subject to wider discussions." 11

In the 29 December 2006 merger of AT\&T and BellSouth, the merged company undertook various commitments not to block other companies' applications directed

\footnotetext{
${ }^{8}$ R Hahn and S Wallsten “The Economics of Net Neutrality” (Washington, DC: AEI Brookings Joint Center for Regulatory Studies, April 2006). www.aeibrookings.org/publications/abstract.php?pid=1067

${ }^{9}$ R Frieden (2006) "Internet 3.0: Identifying Problems and Solutions to the Network Neutrality Debate" at

http://papers.ssrn.com/sol3/papers.cfm?abstract_id=962181>http://papers.ssrn.com/sol3/papers.cfm?ab stract_id $=962181$

${ }^{10}$ See European Commission (2006) "Staff Working Document," 28 June, at: http://ec.europa.eu/comm/avpolicy/reg/tvwf/modernisation/consultation_2005/index_en.htm, at section 6.4, Net Neutrality.

${ }^{11}$ i2010 High Level Group (2006) The challenges of convergence: draft discussion paper, at http://ec.europa.eu/information_society/eeurope/i2010/i2010_high_level_group/index_en.htm
} 
over the Internet connection provided by the merged company. This consent was extracted by a majority in the FCC. ${ }^{12}$ AT\&T agreed to:

- follow the FCC's four Network Freedoms ${ }^{13}$ for thirty months;

- apply network neutrality principles for its broadband ISP between subscribers and the first Internet exchange point for a period of two years;

- BUT it expressly reserved the option not to apply network neutrality principles for its Internet Protocol Television ("IPTV") service, and to any service beyond the first Internet Exchange point.

Note from the description of the first Internet Exchange or 'handover' point that, though discrimination is typically characterised as behaviour by "last mile" consumer ISPs against content providers (CPs), it can equally be undertaken at peering points by third parties. ${ }^{14}$ I note that such discrimination may possibly be detected by the enduser when it is conducted by its ISP, while a far more pernicious and potentially undetectable discrimination may occur at peering points. ${ }^{15}$ Conventional US economic arguments appear to be broadly negative to the concept of net neutrality. ${ }^{16}$ Net Neutrality has been the subject of legislative proposals in the Congress in $2006 .{ }^{17}$ Werbach, Lehr and others are currently attempting to redefine Net Neutrality in terms of interconnection and other inter-carrier requirements, rather than end-user centred policy. ${ }^{18}$

\footnotetext{
${ }^{12}$ See Freiden (2007), citing AT\&T/Bell South (2006) and the dissent of the Chair of the FCC: "Importantly, however, while the Democrat Commissioners may have extracted concessions from AT\&T, they in no way bind future Commission action. Specifically, a minority of Commissioners cannot alter Commission precedent or bind future Commission decisions, policies, actions, or rules ... To the extent Commission action is required to effectuate these [concessions] as a policy going forward, we specifically do not support those aspects of the conditions and will oppose such policies going forward."

${ }^{13}$ Michael K Powell (2004) February 8, Speech at Symposium on "The Digital Broadband Migration: Toward a Regulatory Regime for the Internet Age" held at the University of Colorado School of Law. "I challenge the broadband network industry to preserve the following Internet Freedoms": Freedom to Access Content; Freedom to Use Applications; Freedom to Attach Personal Devices; Freedom to Obtain Service Plan Information. See http://hraunfoss.fcc.gov/edocs_public/attachmatch/DOC243556A1.pdf

${ }^{14}$ See D Clark "Net neutrality” Keynote speech, Telecommunications Policy Research Conference, GMU Law School, Alexandira, Virgina, 28 September 2006, and M Sirbu "What is the Network Neutrality debate about?" presentation at conference A Workshop on Network Neutrality: American and European Perspectives, Paris, 29 May 2007, for technical possibilities in network architecture.

${ }^{15}$ The debate in regard to the subtleties of service degradation is beyond this paper and experts at the Paris conference of 29 May 2007 were divided as to whether degradation that is deliberate could be well enough disguised to suggest off-net discrimination.

${ }^{16}$ See G Woroch, "Open Access Rules and Equilibrium Broadband Deployment” in Cooper and Madden (eds), Frontiers of Broadband, Electronic and Mobile Commerce, Springer 2006, and A Thierer "Net Neutrality: Digital Discrimination or Regulatory Gamesmanship in Cyberspace?" (2004) Policy Analysis 507.

${ }^{17}$ Communications, Consumer's Choice, and Broadband Deployment Act of 2006, at: http://thomas.loc.gov/cgi-bin/bdquery/z?d109:SN02686: @@ @\&summ2=m\&

${ }^{18}$ Work-in-progress papers presented in autumn 2006 at TPRC and Wharton Colloquia.
} 
I briefly introduce the types of discrimination that may occur, issues of QoS, usergenerated and/or distributed content, and broadband supply and investment in the following sections.

\section{Types of content discrimination}

I suggest the following types of discrimination might constitute the type of "nonneutral" behaviour by ISPs that may be found to be harmful to consumer welfare: non-transparency and misleading advertising, "throttling" or blocking, charging, certain types of more extreme and anti-competitive "walled gardens." 19

\subsection{Transparency failures}

ISPs may fail to tell customers and application developers which services they offer estimated bandwidth, latency, etc. This is essential to certain applications, which cannot run with latency, or which are blocked or filtered. Even where there is regulatory commitment to enforce Net Neutrality, the evidential problem remains. Van Schewick ${ }^{20}$ has recently suggested that the main problems currently lie in mobile networks, where VOIP is routinely degraded or blocked. ${ }^{21}$ The problem here is that certain users are breaching their terms of use but being insufficiently or nontransparently sanctioned, and certain programmes are being throttled but the same applies. Often a security justification ${ }^{22}$ is used and is often unchallenged by regulators.

\subsection{Blocking and traffic shaping}

Blocking or "throttling" is the furthest deviation from neutrality. Some economists think it justified, but the basic problem is a distortion of competition between the blocked and unblocked companies. For example, a company serving online gaming content from South Korea may typically choose to do so via P2P networks, whereas an American CP might use a premium service sanctioned by the ISP of the end-user. Not only is the South Korean CP discriminated against, but neither end-user nor CP may be aware of the nature of the problem. ${ }^{23}$ This creates confusion amongst users as

\footnotetext{
${ }^{19}$ With walls sufficiently high that one might term them "Forbidden Cities". The reference is to the Chinese Emperor's official residence in Peking until 1924, and I acknowledge fully the analogy to the 'Great Firewall of China' - on which see J Zittrain and B Edelman, "Internet Filtering in China, Los Alamitos" (2003) CA : IEEE Computer Society Publications Office, and J Goldsmith and T Wu, Who Controls the Internet? Illusions of a Borderless World, Oxford University Press, Oxford (2006).

${ }^{20}$ B Van Schewick, “Towards an Economic Framework for Network Neutrality Regulation” paper presented at The 33rd Research Conference on Communication, Information and Internet Policy (TPRC 2005).

${ }^{21}$ Kocsis and De Bijl have proposed a game theoretical perspective to analyze such incentives similar to the Appendix in Marsden 2006. Kocsis, Viktória and P W J de Bijl, "Network neutrality and the nature of competition between network operators", TILEC Working paper September 2006.

${ }^{22} \mathrm{P} 2 \mathrm{P}$ networks carry malware, spyware, spam and other unsolicited and potentially harmful content.

${ }^{23}$ T Greenberg and A Veytsel, "Every Time You Vote against Net Neutrality, Your ISP Kills a Night Elf” (November 2006) at http://www.ramprate.com/marketcommentary/neutrality.html
} 
to whether and how content is "throttled". Certain types of traffic that are highly valued by the end-user of the Internet can be discriminated against in whole or in part by service providers that are not dominant. This is because they either have good competitive or good traffic management reasons to do so - it makes their networks safer and more efficient, making it complicated to work out when their discrimination is motivated by arguably less benevolent factors, like blocking the competition. There can be motives to throttle content no matter what ISP is discussed, and that behaviour is potentially anti-competitive. Future networks may try to cap P2P more effectively, which can itself lead to an "arms race" between encrypted P2P content and attempts by ISPs to detect P2P traffic. This is an example of how a baseline of traffic and usage would help the regulator to understand the importance of claims made by stakeholders.

\subsection{Termination fees for content providers}

Since broadband ISPs have a termination monopoly or duopoly ${ }^{24}$ over the end-user, they can use that to charge termination fees to those who wish to get access to the user. This behaviour is familiar to the cable TV industry, where only large CPs can secure free or even profitable carriage, whereas smaller CPs with less contracting power are forced to pay the cable TV operator for access. The fear is that a similar model will be imposed on the Internet, where only large CPs with sufficient negotiating power, and those with political influence to secure favourable carriage terms, will secure free carriage. The argument in Europe is particularly pernicious because public service broadcasting (PSB) occupies a position of strong bargaining power with legislatures and regulators. The argument can therefore be characterised as: will Net Neutrality apply only to PSBs, or to other/all content providers? We consider a different set of $\mathrm{CP}$ preferential treatments below.

\section{4 "Walled gardens" or preferred partners}

Carriers can offer exclusive, preferential treatment to one application provider over others, creating a type of "walled garden" of preferred suppliers. This is less distorting than blocking, depending on the type of walled garden and the 'height of the walls'. I can differentiate "walled gardens" from an open/interoperable access "commons." 25 A "walled garden" is a type of IP content service offered without access to the wider Internet: for instance, most mobile telephone networks provided walled gardens to their subscribers. This has wider regulatory implications, involving the development of "gatekeepers" rather than open access models. ${ }^{26}$ Take an example: Mobile users

\footnotetext{
${ }^{24}$ As there is usually only a telephone line, and sometimes a cable line (depending on cable industry development), into each domestic household, there are only two possible competitors unless one or both lines are shared with other rivals.

${ }^{25}$ This is a well-developed distinction discussed at length in our previous report for Ofcom (Marsden, 2006). By 'commons', we refer to an open space, with interoperable and publicly available standards, of which the World Wide Web is the archetype.

${ }^{26}$ Continuing the analogy with commons and walled gardens, one can imagine that a walled garden can be protected and entry or exit charges imposed. By contrast a commons is open access, with no controls. The walled garden gatekeeper is likely to be the owner of the garden - the operator. 'Walled gardens' have historically described content or services bundled by an access provider as a package with fixed or mobile Internet access. The content is usually supplied under contract by content/services
} 
inhabit a much more personal and pervasive environment than fixed Internet users. Compared to fixed line Internet access there are additional constraints on full openness. The mobile industry has developed hitherto on the basis that operators control the use of their networks and the devices which connect to them. For that reason, the initial content offerings of mobile providers have tended to be provided in a "walled garden", in which the customer experience is "guaranteed" by the operator and discriminatory pricing can be imposed on third-party content providers through their contracts with the mobile operator.

In a "walled garden", the number of CPs is effectively regulated by their relationship with an ISP. "Walled gardens" may evolve so that access providers (both mobile and fixed) are likely to continue to offer content and services to their customers, bundled with BB access. These services are often provided with guaranteed QoS (e.g. IPTV services Sky On Demand or Homechoice). These services are not necessarily anticompetitive if the end user can access the wider Internet and choose to consume other content. The critical competition issues are:

- Access providers who provide bundled services could be motivated to degrade content services or applications which compete with their own portal services;

- If they do this, they will not be incentivised to tell their customers that the QoS for these services is inferior;

- They could use this to leverage payment from content and applications providers;

- Access providers may agree preferential arrangements with some content or applications providers but not make the same terms available to others.

It is clear that discrimination and other forms of quality control are exercisable in a manner which does not fully support open access to content.

\section{Quality of Service}

Content charging relies on a type of QoS for the Internet, enabling network providers to discriminate between packets, and potentially even content providers, to offer better than 'best effort' quality. There is an argument that the Internet should not develop QoS, and that therefore no filtering of packets or preferential increase in quality should be allowed. ${ }^{27}$ As Internet engineering has for many years pursued the goal of increased reliability, speed and higher bandwidth, this position is opposed by Clark $^{28}$ and Crowcroft. ${ }^{29}$ The current 'best effort' Internet has flaws, as Yoo ${ }^{30}$ states:

providers and presented to the end user by the access provider as a branded 'portal'. The content or service can be acquired from a third party in exchange for a direct payment. An agreement to share advertising revenue is an increasingly common model. The service offered by an access provider may restrict users to content only in that walled garden. In this case, the access provider is a gatekeeper (like Vodafone Live! When it first launched). Alternatively, the access provider may give users the freedom to access the wider Internet and consume other content and services, including those which may compete with those in the portal. In this case, he is not a gatekeeper to the Internet (like the BT Yahoo! model).

${ }^{27}$ Wikipedia, Packet sniffer; available at: http://en.wikipedia.org/wiki/Packet_sniffer

${ }^{28}$ D Clark (28 February 2007) “The end-to-end argument in today's world: Do we have to destroy the principle to save it?" http://www.communicationsresearch.net/events/article/default.aspx?objid=1835 
"TCP/IP routes packets anonymously on a 'first come, first served' and 'best efforts' basis. Thus, it is poorly suited to applications that are less tolerant of variations in throughput rates, such as streaming media and VOIP, and is biased against network-based security features that protect e-commerce and ward off viruses and spam."

The standards body for 3G mobile telephony, 3GPP, has been working since 2000 on a set of standards called IMS, for IP Multimedia Subsystem. ${ }^{31}$ This is an operatorfriendly environment intended to generate new revenue via deep packet inspection. Fixed-line carriers and equipment vendors have created the "IPsphere", a new set of standards for network intercession in IP application flows. ${ }^{32}$ Both sets of standards support the ability to filter and censor by file type, and potentially content provider, on the Internet: in an extreme case, one could degrade all content that is not tagged as paying a 'premium' carriage fee. This enables the carrier to discriminate, to decide which content to delay and which to permit to travel at normal speeds to the end-user. As Waclawsky puts it: "This is the emerging, consensus view: That IMS will let broadband industry vendors and operators put a control layer and a cash register over the Internet and creatively charge for it." ${ }^{33}$ Of course that also can lead to a type of "arms race" as P2P networks encrypt all traffic to prevent inspection, in the same way that firewalls on Intranets were evaded using Port:80 and other techniques. ${ }^{34}$

Odlyzko and Levinson ${ }^{35}$ refute many of the arguments for fine-scaled charging which underlie the architecture of IMS, and QoS. They note that:

"Technology appears to be making fine-scale charging (as in tolls on roads that depend on time of day or even on current and anticipated levels of congestion) increasingly feasible. Standard economic theory supports such measures, and technology is being developed and deployed to implement them. But their spread is not very rapid, and prospects for the future are uncertain ... the case for fine-scale charging is not unambiguous, and in many cases may be inappropriate."

\footnotetext{
${ }^{29}$ J Crowcroft (2007) "Net Neutrality: the technical side of the debate. A white paper" (2007) 37 ACM SIGCOMM Computer Communication Review 1, at $49-56$.

http://portal.acm.org/citation.cfm?id=1198255.1198263\&coll=ACM\&dl=ACM\&idx=J101\&part=news letter \&WantType=Journals\&title=ACM\%20SIGCOMM\%20Computer\%20Communication\%20Revie $\underline{\mathrm{w} \& \mathrm{CFID}=15151515 \& \mathrm{CFTOKEN}=6184618}$

${ }^{30}$ C S Yoo, "Beyond Network Neutrality” (2005) 19 (1) Harvard Journal of Law \& Technology.

${ }^{31}$ See J Waclawsky (2005) "IMS 101: What You Need to Know Now", at: http://www.bcr.com/carriers/public_networks/ims_101_what_need_know_now_2005061514.htm

${ }^{32}$ See IPSphere (2006) 'Creating a Commercially Sustainable Framework for IP Services Realizing Next Generation Revenues', IPsphere Forum Work Program Committee Version 1b.0, May, at: http://www.ipsphereforum.org/home/IPsphere_CommercialPrimerExec050806.pdf

${ }^{33}$ Waclawsky (2005) supra.

${ }^{34}$ C Pfleeger and S L Pfleeger, Security in Computing, $4{ }^{\text {th }}$ Edition, Prentice Hall Pearson, 2006.

${ }^{35}$ A Odlyzko and D Levinson (2007) "Too expensive to meter: The influence of transaction costs in transportation and communication" http://www.dtc.umn.edu/ odlyzko/doc/metering-expensive.pdf
} 
I see no obligation to take any firm position on the issue. What is important in this discussion is the extent of such potential discrimination, and its justification. Freiden ${ }^{36}$ "accepts as necessary and proper many types of price and QoS discrimination" and attempts "an identification of best practices in "good" discrimination that should satisfy most network neutrality goals without creating disincentives that might dissuade ISPs from building the infrastructure needed." That is also my goal, in a specific European context.

\subsection{Bandwidth Supply: Traffic shaping and content "throttling"}

All network owners have incentives to stop traffic flowing over their networks that is low value, high volume and for which it is technically unfeasible or uneconomic to charge - notably non-network affiliated content including user-generated and transmitted content. This content is very low-value to the network and, with many millions of users all valuing each others' own-created Web 2.0 content, under current market and technological conditions there is insufficient value to charge individual users and thus all content may be throttled in the absence of a charging mechanism. Content on limited bandwidth networks can "choke" the network capacity, especially at peak times of usage (daytime for business, evening for consumers). In a "best effort" environment without congestion charging, ${ }^{37}$ that content has insufficient disincentives to prevent its flourishing: for instance P2P traffic and its use by earlyadopter high-volume users. ISPs can choose to filter P2P traffic of various kinds typically it is unencrypted relatively crude versions of popular file-sharing programmes, such as BitTorrent which is used to provide upgrades to the most popular multiplayer online game World of Warcraft. Many assertions are made about the implications of certain types of traffic, but regulators currently have no basis for deciding if such assertions represent real problems. ${ }^{38}$

Blocking (and other forms of traffic shaping) is controversial because, under current network management tools, it is a blunt tool. For instance, all P2P traffic using a certain protocol (e.g. BitTorrent) may be blocked. P2P can respond by encrypting its traffic or otherwise spoofing, but this creates an "arms race" much like that found in security software responses to the threat of breaches. In fact, the claims of ISPs are that $\mathrm{P} 2 \mathrm{P}$ traffic contains a high proportion of malware, spam and spyware, and therefore it is filtered in the end-user's interest and in conformity with the Terms of Use for end-users. ${ }^{39}$ Many assertions are made about the implications of certain types

\footnotetext{
${ }^{36}$ R Frieden (2006), see footnote 9.

${ }^{37}$ J Crowcroft "Net Neutrality: the technical side of the debate. A white paper" (2007) 37 ACM SIGCOMM Computer Communication Review 1, at 49 - 56. http://portal.acm.org/citation.cfm?id=1198255.1198263\&coll=ACM\&dl=ACM\&idx=J101\&part=news letter\&WantType=Journals\&title=ACM\%20SIGCOMM\%20Computer\%20Communication\%20Revie $\mathrm{w} \& \mathrm{CFID}=15151515 \& \mathrm{CFTOKEN}=6184618$

${ }^{38}$ Public remarks of discussion between UK and French regulators at ENST conference 29 May 2007 in Paris.

${ }^{39}$ See R Clayton "Failures in a Hybrid Content Blocking System.” Proc. 5th Workshop on Privacy Enhancing Technologies, Dubrovnik, May 2005, from http://www.cl.cam.ac.uk/ rnc1/cleanfeed.pdf, and I Brown, "Internet censorship: be careful what you ask for." Proc. International Conference on Communication, Mass Media and Culture, Istanbul, October 2006, C Pfleeger and S L Pfleeger Security in Computing, $4^{\text {th }}$ Edition, Prentice Hall Pearson, 2006.
} 
of traffic, but regulators have no basis for deciding if such assertions represent big or small problems. The ISP assertion that $\mathrm{P} 2 \mathrm{P}$ traffic contains a high proportion of malware may be disingenuous. Email spam and web surfing are the vectors for malware, but the ISPs do not block such traffic. ${ }^{40}$ The ISP assertion that for instance BitTorrent traffic contains a high proportion of malware may be correct or disingenuous. Email spam and web surfing are the vectors for malware, but the ISPs don't block such traffic.

The claim made is that networks cannot be upgraded successfully given the flood of $\mathrm{P} 2 \mathrm{P}$ traffic. This is by no means a universally shared sentiment amongst ISPs and I note recent comments attributed to Matt Beal, BT Wholesale's chief technical officer: "It is up to us at the core of the network to make sure there is enough bandwidth". ${ }^{41}$ He further stated BT's Next Generation Network ${ }^{42}$ would "put enough [bandwidth] volume out there ... so we don't have to [traffic shape]" which is "quite Big Brother-ish". There is therefore no consensus as to the type and extent of traffic shaping and other forms of blocking and throttling P2P traffic. Where ISPs do not have effective Terms of Use, or do not enforce uniformly those current strategies in place to dissuade "unfair" use, two consequences can follow.

1. Users are summarily terminated or suspended - this can be conducted by any ISP and may well be justified. This practice could be made more transparent. ${ }^{43}$

2. ISPs choose to filter $\mathrm{P} 2 \mathrm{P}$ traffic - typically popular file-sharing programmes.

Some content providers (for example Google and Akamai) also invest in network infrastructure (called Content Delivery Networks or CDNs) that minimise the end-toend bandwidth required of the carrier's network in order to improve the user experience, and consequently minimise the need for the carrier to invest in backbone and exchange capacity. The CDN stores ("caches") content within countries and even networks, in order to deliver the content more efficiently and quickly than if there were only one global server to deliver all content. There is a research question that may be considered: would the introduction of QoS and discrimination enhance or diminish the business case for such local storage that is not on the network? More research is required on this topic, as it may be that NGN content discrimination could begin an "arms race" for local storage solutions between ISPs and CDNs. It is clear that such a competition would require extra resources above and beyond entry into content markets, and the prospects for European content development should be considered in the light of such potential costs. I consider it in the following section.

\footnotetext{
${ }^{40}$ See C Williams "Virgin throttles national cable network" 8 May, 2007, The Register, at http://www.theregister.co.uk/2007/05/08/vigin_nationwide_throttling/

${ }^{41}$ D Meyer, "BT says no to traffic shaping" ZDnet, Thursday, April 12, 2007, at http://uk.news.yahoo.com/zdnet/20070412/ttc-bt-says-no-to-traffic-shaping-20a87fa.htm

${ }^{42}$ A common ITU term for all-IP networks, which are replacing the current telephony networks.

${ }^{43}$ Freiden sites Code Monkey Ramblings Blog "Network Neutrality”, posted May 20, 2006. http://www.codemonkeyramblings.com/2006/05/network_neutrality.php: "What the ISPs don't tell the public is that there are no free-riders among the content companies. They pay handsomely for their bandwidth. In fact, they are the true bread and butter for the major telecoms and ISPs. The reason that this "Network Neutrality" controversy exists today is that ISPs don't want to admit that their whole business model is flawed."
} 


\subsection{Supply and investment}

Most existing UK home Internet connections are already at broadband speed. There may be a developing supply-demand "arms race", as connection speed and application bandwidth continually drive each other higher (at least in urban highdensity locations). This is obviously only one of several different potential outcomes. If networks and commercial content providers cannot monetise their respective parts of the value chain, network effects can reverse into a "vicious circle", in which neither content nor network can secure investment to provide service. ${ }^{44}$ Instead, the inflexion points at which investment in the lagging element is needed to prime the next phase of disruptive growth can become crisis points. At this point, investments may be constrained and a "virtuous circle" of investment replaced by a vicious circle of under-investment. As users currently display relatively little apparent motivation to price-discriminate in order to gain greater bandwidth, knowing that the extra bandwidth is only in the 'last mile' and does not necessarily result in higher speeds for their favourite service, the incentives for end-users to signal willingness to pay for greater service may be weak. Again, there is an information problem, with ISPs unwilling to demonstrate clearly the practical advantages of advertised speeds of for instance "up to $8 \mathrm{Mb} / \mathrm{s}$ ". This investment conundrum is claimed by some ISPs as a justification for traffic management and price discrimination, two of the types of content discrimination I discuss in the following section.

\section{Consumer and User demands for content}

\subsection{Web 2.0 and Service/Content Innovation}

User-generated and distributed applications and services on the Internet are seen as crucial to development of the broadband economy, increasing the utility and power of networked computing, especially the Internet. As Commissioner Reding stated:

"We are now living through a new disruptive phase of the Information Society. Some people call it Web2.0 or social networking. I can list some of the components: blogs, podcasts, wikis, social networking websites, search engines, auction websites, games, VoIP and peer-to-peer services. What is new about these uses of the Internet is that they exploit the Internet's connectivity to support people to network and to create content. This is a new paradigm in which users are co-producers of services. "45

Web 2.0, makes user-generated and distributed content central to consumers' Internet experiences. This phenomenon has fundamental impacts on the value chain of

\footnotetext{
${ }^{44}$ Odlyzko states that: "Lack of quality statistical data was a prime source of the way many investors and decision makers in competing operators misled themselves around 1999 by following the hearsay on growth and focussing on whacky measures of value, while underestimating the real cost drivers." Odlyzko (2004) “The many paradoxes of broadband" http://firstmonday.org/issues/issue8_9/odlyzko at Table 4.

${ }^{45}$ See V Reding, (2006) "The Disruptive Force of Web 2.0: how the new generation will define the future" SPEECH/06/773 at http://europa.eu/rapid/pressReleasesAction.do?reference=SPEECH/06/773\&format=PDF\&aged=0\&lan guage $=$ EN\&guiLanguage $=$ en
} 
affected industries. ${ }^{46}$ Notable European examples are VOIP software Skype and the P2P client Kazaa. User experience with digital games and multimedia suggests that they are likely to drive innovation and adoption of Web 2.0 and P2P services and markets. $^{47}$ Ruthless competition in these markets results in highly volatile and "snowballing" investment decisions: for states seeking to attract such investment, there is more of a "winner-takes-all" pay-off from the entrepreneurial investment climate provided. ${ }^{48}$

If innovation is typically both user-distributed and user-driven, the implications are that innovation is encouraged by interoperability and open access: in general, ensuring that content can be freely shared between those users. This view is in some conflict with content and network owners' desire to be recompensed for provision of local loop upgrades and has led to an animated debate in the United States. Note that content providers pay for their traffic to be carried by backbone ISPs, on a best effort basis, and the argument is about ISPs wishing to increase those payments as a result of either enhancing or blocking service, on a mandatory or opt-in basis (clearly a mandatory blocking service for those refusing to pay an extra toll is the most capricious of these possibilities, as in Madison River).

Lemley and Lessig claim that innovation at the edge of the network is opposed by traditional media and network businesses, as it makes business cases based on controlling distribution bottlenecks redundant: where there is peer sharing, there is less opportunity for traditional bottlenecks and therefore control of revenues. However, the inverse applies also: without some means to secure revenues for the increased bandwidth necessary for Web 2.0 type applications to flourish, do network operators have an incentive to upgrade? As Whitacre of AT\&T famously stated:

"The Internet can't be free in that sense, because we and the cable companies have made an investment and for a Google or Yahoo! or Vonage or anybody to expect to use these pipes [for] free is nuts! ",49

Web 2.0 content is the most susceptible to discriminatory pricing and therefore forms a focus for the discussion of discrimination that follows. A goal of the European Commission is to encourage the development of European content providers to match the American success stories: "The creation of an open and competitive single market for online content is one of the key aims of the EU's i2010 initiative." ${ }^{, 50}$ The European approach to "Content Online" is to be laid out in a Communication from the European Commission, expected in the autumn of 2007. Therefore the European user generated content industry's future entry barriers and business model are at stake in this debate, a fact of which the Commission and Member States are aware and which needs to be

\footnotetext{
${ }^{46}$ See for example B W Wirtz "Reconfiguration of Value Chains in Converging Media and Communications Markets" (2001) 34 Long Range Planning, 489-506.

${ }^{47}$ C Marsden, J Cave, E Nason, A Parkinson, C Blackman and J Rutter, (2006) Assessing Indirect Impacts of the EC Proposals for Video Regulation, TR-414 for Ofcom. Santa Monica: RAND

${ }^{48}$ See M Katz and C Shapiro "Technology Adoption in the Presence of Network Externalities" (1986) 94 (4) Journal of Political Economy, 822-41.

${ }^{49}$ Business Week International Online Extra, “At SBC, It's All About 'Scale and Scope”, 7 November, 2005 at: http://www.businessweek.com/@@n34h*IUQu7KtOwgA/magazine/content/05_45/b3958092.htm

${ }^{50}$ See http://ec.europa.eu/avpolicy/other_actions/content_online/index_en.htm
} 
fully considered in future policy discussions in order to take a holistic view of the problem.

The questions I explore here regard the barriers to entry for European content providers. Would content-sharing sites develop if discriminatory content charging was the state of the world? Furthermore, the network effects required to make content successful may only be possible because content sites do not initially seek to monetize content: monetization is enabled because the network effect created a critical mass of contributors and consumers. The "next" YouTube may face disincentives to achieve such growth.

\subsection{The user as citizen: Internet access policy}

Many European citizens will want to use Web 2.0 services to share photographs, music and other user-generated content. Users whose access to Internet content is 'throttled' have reportedly 'flamed' or sent abusive email to ISP owners. Users increasingly expect a level of unfiltered access to 'free' content on the Internet, and it is possible that this will be confirmed by a redefinition of access policy in the near future. We may expect to see more protest behaviour by 'netizens' who do not agree with a law or policy, especially where ISPs are seen to have failed to fully inform end-users about the implications of policy changes. Regulators (and their political equivalents) will not be able to ignore such problems. ${ }^{51}$

A type of Universal Service Obligation (USO) that is upgraded as broadband network speeds increase can ensure a minimal open Internet layer is maintained. I do not in this paper take any position on whether the USO will be extended for NGNs, nor is it possible to do so in an environment where the future bandwidth supply/demand capabilities are so uncertain. However, I raise the issue - which is part of a current European Commission research project ${ }^{52}$ - in order to emphasise that the debate is broader than the question of application of competition law, and encompasses societal needs and consumer rights.

\section{A European approach to Net Neutrality?}

Our approach is of the "middle way" proposed by Atkinson and Weiser" and Freiden. ${ }^{54}$ It neither proposes an absolute ban on price discrimination where justified (for example, where higher speed access to fibre links to the consumer provides an investment that certain high-bandwidth applications find attractive), nor an absolute prohibition on regulatory oversight. Instead it begins by asking which abuses are key to the problem in Europe. I have identified an immediate problem requiring regulatory oversight that is counter-intuitive: the immediate problem with Net Neutrality may not be so much with the dominant ISP (expressed in European debate as one having

\footnotetext{
${ }^{51}$ Even if they do not reach the level of the Swedish "Pirate Party": see http://www2.piratpartiet.se/international/english

${ }^{52}$ RAND team members attended a workshop at the Joint Research Centre in Seville, which discussed scenarios for USO, on 19 April 2007.

${ }^{53}$ R D Atkinson and P Weiser, “A 'Third Way' on Network Neutrality”, May 30, 2006, available at SSRN: http://ssrn.com/abstract=1004522

${ }^{54}$ See footnote 9 .
} 
Significant Market Power [SMP]), ${ }^{55}$ but with the smaller ISPs. It may be a disguised economic incentive problem that is first identified as a security issue. It may further impact relations between ISPs, in that those (typically smaller consumer) ISPs that are generating most spam can adversely affect the security and traffic management of other networks, and cause particular problems at peering points.

There may therefore be a case for identifying the non-SMP operators as the current miscreants in NGN access-to-content policy. I suggested that widespread discriminatory behaviour can take place even where an ISP does not have SMP. Competition between ISPs is present in some metropolitan and suburban networks, but is limited by both geographical scale and feature-price scope. ${ }^{56}$ Note that where only retail resellers use a broadband line from the incumbent, the degree of price and feature competition is very small given that wholesale prices and bit-rates are set by the incumbent. It is therefore an easy generalisation to claim greater broadband competition in Europe, when for infrastructure (where real investment is made and real innovation in service is possible) this may not be the case either currently or in the near future. ${ }^{57}$ In any case, it is a very untypical, highly sophisticated and motivated consumer who currently is able to analyze the different bandwidth and throttling options and select to which provider to switch at the end of their contract.

\subsection{Watch list for regulators}

The main point that emerges from the scenario portraits is that market evolution is dynamic and complex. The availability and design of a suitable regulatory response must reflect this dynamism, and also the responsiveness of regulators and market players to each other. Therefore, if any legislation is required it should be future-proof and avoid being overly prescriptive, to avoid a premature response to the merging environment. Instead, I propose below that regulators equip themselves with the skills and evidence base to rapidly investigate potential problems of unjustified discrimination. Further, I note that the European legal basis for regulatory intervention, especially the Access and Interconnection Directive, potentially provides for a wider and better variety of regulatory tools to intervene than the current US situation. $^{58}$

Two specific issues in this "watch list" are detection of any discrimination, and the standing of the content providers complaining of such discrimination. Engineers appear unable to agree on whether QoS will be introduced in NGNs, as QoS is a very longstanding issue that has never been implemented with commercial success on the

\footnotetext{
${ }^{55}$ See the European Commission guidelines: http://ec.europa.eu/comm/competition/liberalization/others/i02_1016_en.pdf

${ }^{56}$ Note that of Europe's $450 \mathrm{~m}$ population, only a small proportion are in reach of an unbundled local telephone exchange, or an alternative high-speed infrastructure provider to the duopoly of cable and telecoms incumbents. See the EC Implementation Twelfth report of 29 March 2007 at

http://ec.europa.eu/information_society/policy/ecomm/implementation_enforcement/annualreports/12t hreport/index_en.htm or the ECTA Regulatory Scorecard: http://www.ectaportal.com/en/upload/File/Broadband\%20Scorecards/Q306/FINALBBScQ306.xls

${ }^{57}$ R Van Der Berg, "Developments In Fibre Technologies And Investment”, OECD draft, DSTI/ICCP/CISP 4, 3 May, 2007 OECD, Paris.

${ }^{58}$ D Scott, Speech at Westminster eForum, 2007, at http://www.wwww.radioauthority.org.uk/media/speeches/2007/03/regulate
} 
public Internet. However, should it be introduced, the types of harmful discrimination that can result may be undetectable. Blocking, as discussed in section 1, is relatively easy to spot. "Throttling" or choking bandwidth, even where unjustified, may be harder to spot and even harder to efficiently regulate. It is a moot point whether unjustified discrimination short of blocking is useful to an ISP, as discrimination against a particular content type may be overcome by sophisticated content providers via encryption in a technological "arms race", 59 and in order for discrimination to create a business case, it needs to be effective in creating substantial incentives for content providers to pay a premium. Though it may not be possible technically to identify all discrimination, the most egregious types of discrimination may only provide a marketing advantage if obvious enough for customers to identify the benefits. $^{60}$ Paradigmatically, only clear discrimination may be really worthwhile for network operators - such that the cost-benefit is at least in theory obvious to content suppliers, network operators and end-users. A solution may be to require network operators to provide their Service Level Agreements on QoS to both content providers and more transparently to the end-user via a regulatory or co-regulatory reporting requirement.

Regulators expecting a 'smoking gun' to present itself as in Madison River should be advised that a more proactive approach to monitoring and researching non-neutral behaviours will make network operators much more cognisant of their duties and obligations - to do so without incurring the interest of a concerned regulator may be hazardous. Regulators can monitor both commercial transactions and traffic shaping by ISPs to detect potentially abusive discrimination. The question of legal standing for content providers under Directives is a technical legal question that I leave open in this paper, but upon which there is a need for greater discussion in the European Regulators Group (ERG) and elsewhere. ${ }^{61}$ The European Commission has asked in the ERG "if discussion should not be dealing with Net Neutrality issues". ${ }^{2}$

If content providers cannot formally make individual complaints to regulators, it may be that an independent investigation into potential discrimination can be made on the regulator's own initiative, depending on its constitutional and formal powers. While this is appropriate for a converged regulator such as UK Ofcom which regulates both content and carriage, it may not be the case in other European jurisdictions. Both the European Commission and ERG would be well-advised to consider the types of response regulators could make to such complaints if standing is found to be lacking. No matter what theoretical powers may exist, their usage in practice and the issue of forensic gathering of evidence may ultimately be more important. An ex ante

\footnotetext{
${ }^{59}$ These types of escalation between more sophisticated encryption and more sophisticated detection are of benefit to encryption and decryption software and hardware engineers, but not necessarily the end-user.

${ }^{60}$ Discussion amongst a panel of ten Tier 1 network engineers and policymakers at the Paris conference 29 May 2007 revealed that while it was quite possible to disguise discrimination at the margins, no incentives appeared to exist for such small-scale and subtle (i.e. also expensive and sophisticated) discrimination.

${ }^{61}$ The ERG consulted in 2007 on NGN access, in ERG (2007) ERG Consultation Document on Regulatory Principles of NGA (ERG (07) 16 at http://www.erg.eu.int/doc/publications/consult_regprinc_nga/erg_cons_doc_on_reg_princ_of_nga.pdf

${ }^{62}$ http://erg.eu.int/doc/meeting/erg_06_80_19th_plenary_conclusions.pdf
} 
requirement to demonstrate internal network QoS metrics to content provider customers and consumers may therefore be a more practical solution.

Currently, not only is it not a requirement for ISPs to notify customers when they block vital P2P-distributed applications, the security reasons given are outside the remit of typical economic telecoms regulators. This governance gap has been highlighted to Ofcom at the most senior levels, and is partially overcome by the institutional arrangements in the European Commission. Where the security reasons given by ISPs for blocking traffic (which they claim carries malware and other harmful content) is typically the concern of the Ministry of the Interior (in the UK, the Home Office) and occasionally the Ministry of Trade and Industry, the regulator defers to these senior agencies and has little technically-specific knowledge of data security. ${ }^{63}$ In Directorate General Information Society and Media (DG INFSO), the Unit that covers information security is at least in the same DG as the enforcement and policy units.

Therefore, I suggest that the European NGN content problem is less a lack of regulatory tools per se than it is a lack of forensic skill to analyse the potential consumer harms that can be created by unjustified discrimination. It is important that governments consider where best the issue is regulated, by telecoms regulator or by ministry. Because Net Neutrality raises a set of new issues for regulators, the necessary skill set needs to be acquired and developed in consultation with other national and international regulators, and the European Commission. Note in this regard the work of the OECD, the bilateral relations with the US, and the European Regulators Group Convergence working group. ${ }^{64}$

\subsection{Co-regulatory solutions}

Note one critical proviso: regulation to ensure any form of Net Neutrality in Europe should have as light touch as possible, while maintaining effectiveness, based on three recourses:

1. Information regulation, to require service providers to inform consumers about the choices they are making when they sign up for a service, and any relevant changes to the service - for instance blocking of certain services. The relevance of the changes is consumer-driven, and therefore full and prompt disclosure by companies via their website is necessary. Even if not all customers choose to exercise the option to monitor the situation, providing the

\footnotetext{
${ }^{63}$ See I Brown, L Edwards and C Marsden “ Legal and institutional responses to Denial of Service Attacks" Communications Research Network/Department for Trade and Industry joint seminar on Spam/DDoS, 13 November, 2006 at http://www.communicationsresearch.net/events/article/default.aspx?objid=1464

${ }^{64}$ See European Regulators Group (2007) 07(01) Working Programme for 2007 at http://erg.eu.int/doc/work_progr_2007/erg_07_01_work_programme_2007.pdf at p7: "ERG will consider the processes of convergence and the development towards a multi-play communications market as a topic for 2007. Convergence also impacts the relationship between communications and broadcasting markets (mobile-TV). Access to content (i.e. issues in distribution and conditional Net Neutrality, not content regulation, which falls outside the scope of the framework), net-neutrality, interoperability, bundling of broadband services (flat-rate, triple and quadruple play offers) and consumer protection issues could be successfully investigated by ERG WGs and PTs."
} 
information provides transparency. It also may head off calls to helpdesks given that the 'technical fault' may actually be a change of network policy.

2. Continually upgraded monitoring and surveillance.

3. Where necessary investigation and timely but evidence-based intervention, to correct harmful and unjustified discrimination

These regulatory interventions do, however, require regulators to impose a reporting burden on service providers to provide transparency in their traffic-management practices. ${ }^{65}$ I note that the danger of fragmentation and regulatory arbitrage is apparent here for two reasons: a type of "regulatory holiday" for ISPs in one country but not another is quite likely, and enforcement of Net Neutrality may be highly divergent even under the current 2002 framework. Therefore the EC as well as Member States will need to monitor developments in this area closely, especially in view of policies for ContentOnline and the wider 'Lisbon goals', under which the importance of content provision (as well as network deployment) for jobs and growth are emphasised. ${ }^{66}$ In particular the role of SMEs in content and service provision is likely to be a substantial engine for such growth.

Notwithstanding the backstop of regulatory intervention, based on the incomplete evidence thus far, I suggest that Net Neutrality be primarily enforced via reporting requirements. This is a form which can be classed as self-regulation where there is an incentive on market players to cooperate, and co-regulation or formal regulation if there is not, in which market actors and self-regulatory bodies maintain a constant dialogue with regulators and consumers. This is a preferable lighter-touch regime to those of government-funded regulation and non-regulation of European Net Neutrality and a flexible and responsive framework.

Expanding on the second recommendation, timely and evidence based intervention, I note that regulators will need to ensure that the network operators report more fully and publicly the levels of QoS that they provide between themselves as well as to end-users. Internet architecture experts have explained that discrimination is most likely to occur at this level as it is close to undetectable by those not in the two networks concerned in the hand-over of content. ${ }^{67}$ It is very difficult (if not impossible) to monitor the former for anyone other than the two network operators themselves, and therefore shedding light on QoS in this area will require a reporting requirement to be imposed. As this information is routinely collected by the network operators for internal purposes, this should not impose a substantial burden.

The pace of change in the relation between architecture and content on the Internet requires continuous improvement in the regulator's research and technological training. This is in part a reflection of the complexity of the issue set, including

\footnotetext{
${ }^{65}$ This reporting requirement could be provided in a co-regulatory forum, as in codes of practice adoption by, for instance, the Internet Service Providers' Association (ISPA) in the UK and its counterparts in EuroISPA. However, there will be a need for content provider participation in, and consultation over, such a scheme to ensure it receives full industry backing. Consumers should also be consulted.

${ }^{66}$ See http://ec.europa.eu/avpolicy/other_actions/content_online/index_en.htm

${ }^{67}$ This information is both the subject of Professor David Clark's comments at the Telecom Policy conference 2006, 29 September, 2006, Alexandria, VA. And also of the experts at the Paris workshop 29 May 2007.
} 
security and Internet-peering issues, as well as more traditional telecoms and content issues. Dominant and entrenched market actors in regulated "bottlenecks" play games with regulators in order to increase the sunk costs of market entry for other actors, and pass through costs to consumers and innovators. Very high entry barrier co-regulation and self-regulation can be as effective in curbing market entry as direct content regulation, especially where ISPs are incentivised to tier and charge for QoS, which raises doubts as to their desire to implement self regulation. By and large, the greater the levels of regulation, the more likely the market is to develop towards more closed and concentrated structures, for three reasons:

1. larger companies are able to bear compliance costs much more easily than SMEs, and therefore it is important that such entry barriers - where necessary - are minimised;

2. larger companies have the resources and lobbying power to seek to influence regulation in a positive direction;

3. large ISPs in a concentrated market may offload costs upstream onto content providers and developers, or downstream onto consumers.

Therefore any solution needs to take note of the potential for larger companies to "game" a co-regulatory scheme and create additional compliance costs for smaller companies (whether content or network operators, and the combination of sectors makes this a particularly complex regulatory "game").

A group of academics and engineers have proposed rules on what can be called "Internet" service. Those rules might be considered a form of transparency regulation. Essentially they claim that any service that differentiates between packets is breaching the end-to-end principles of the Internet Protocol and therefore should not be labelled as an "Internet" service. They suggest legislative wording as follows:

"Network providers that offer special features based on analyzing and identifying particular applications being conveyed by packet transmissions must not describe these services as "Internet" services. Any representation as to the speed or "bandwidth" of the Internet access shall be limited to the speed or bandwidth allocated to Internet access. "68

I do not comment on this proposal, beyond suggesting that regulators will need to form a view of what access to the public Internet is required in order to make effective conclusions on the future for USO during the course of 2007-8. I emphasise that this debate is likely to grow in complexity during that period, and urge regulators to conduct research in this area. Unfettered Internet access of some type is a currently enjoyed "public good" for consumers, particularly in the use of Web 2.0-type applications and services, and this public sphere is a regulatory policy of continued consideration.

\footnotetext{
${ }^{68}$ Internet Platform for Innovation Act, suggested wording (2006) at http://www.dpsproject.com/legislation.html
} 


\section{Conclusion: Regulating for end-users and innovation}

An open content model tends towards Web 2.0-type "public good" values and innovation concentrated in end-users rather than network operators and associated clusters of developers. While this is by no means the only model for Internet-based and ICT-oriented innovation, it is a promising new approach that Commissioner Reding has suggested should be encouraged. At the margin, the choices made now about the regulation of these sectors can have an impact on this business model choice, and therefore end-user benefits.

In sum, these conclusions support a light-touch regulatory regime involving reporting requirements and co-regulation, with as far as is possible, market-based solutions. Regulatory monitoring of potential abuses, including strengthening investigatory capacity and transparency for end-users, is a solution which maintains maximum flexibility and policy choice, while ensuring that any abuses can be quickly detected and dealt with appropriately. Solutions may be international as well as local, and international coordination of best practice and knowledge through fora such as the ERG and OECD will enable national regulators to keep up with the technology "arms race".

Finally, note that the Commission on 14 November 2007 issued new proposed Directives, including network neutrality provisions, explaining that:

In Article $21 \ldots N R A s$ are given powers to require from operators better tariff transparency (paragraph 4) as well as clear information on possible restrictions on access to all types of content and applications (paragraph 5). The possibility for the Commission to take implementing measures is intended to ensure, where appropriate, a minimum level of harmonisation in this area (paragraph 6).

In Article 20(5): this provides for a transparency mechanism concerning possible restrictions on end-users' choice of lawful content and applications in order to empower end-users to make an informed choice of services, thus allowing them to reap the full benefits of technological developments in the Information Society.

In Article 22: this grants to the national regulatory authorities the power to prevent degradation of quality of service by setting minimum quality levels for network transmission services for endusers. The possibility for the Commission to take implementing measures is intended to ensure, where appropriate, a minimum level of harmonisation in this area (paragraph 3). ${ }^{69}$

\footnotetext{
${ }^{69}$ See European Commission (2007) 14 November, Proposal for a Directive Of The European Parliament And Of The Council amending Directive 2002/22/EC on universal service and users' rights relating to electronic communications networks, Directive 2002/58/EC concerning the processing of personal data and the protection of privacy in the electronic communications sector and Regulation (EC) No 2006/2004 on consumer protection cooperation at 8 at http://www.ec.europa.eu/information_society/policy/ecomm/doc/library/proposals/dir_citizens_rights_ en.pdf
} 
As it explained in its Impact Assessment (Section 8.1.4 at p90), ${ }^{70}$ the European Commission favours harmonisation and the granting of updated rights to enforce minimum standards to users, rather than leaving them (as currently) in the hands of regulators:

[W] hile the "net freedoms" are already embedded in the design of the framework, they are expressed as obligations on the undertakings and corresponding powers of the NRA, and not in relation to users' rights to ensure connectivity.... the current regulatory framework does not provide NRAs with the means to intervene were the quality of service for transmission in an IP-based communications environment to be degraded to unacceptably low levels, thereby frustrating the delivery of services from third parties. In such an event, end-users' connectivity to services provided on the Internet (TV, telephony, Internet, etc.) could be at risk. The impact of prioritisation or of systematic degradation of connectivity could be larger on services needing real-time communications (e.g. IPTV, VoIP, in which latency is critical) and ultimately affect end-user choice.

It cites OECD (2007) as authority for this proposition and maintains that intervention is necessary:

This option would address "network neutrality" and basic connectivity by establishing a safety net for quality of transmission: in case the elements of the basic connectivity would become seriously under threat, the NRAs could intervene by setting common minimum quality levels for network transmission services for endusers, based on standards agreed at EU level. This would guarantee minimal level of connectivity and greater choice for consumers ensuring the delivery of third party services at suitably high quality levels appropriate to their needs. Provisions in the area of "net freedoms' would also be made more explicit.

Should these proposals become legislation in 2009 at European level, and therefore 2011 at national level, they may go some way towards satisfying the concerns outlined in this paper with flexible regulatory responses. However, if a week is a long time in politics, four years is an eternity in broadband content development.

\footnotetext{
${ }^{70}$ Impact Assessment (2007) Commission Staff Working Document Impact Assessment Accompanying document to the Commission proposal for a Directive of the European Parliament and the Council amending European Parliament and Council Directives 2002/19/EC, 2002/20/EC and 202/21/EC Commission proposal for a Directive of the European Parliament and the Council amending European Parliament and Council Directives 2002/22/EC and 2002/58/EC Commission proposal for a Regulation of the European Parliament and the Council establishing the European Electronic Communications Markets Authority \{COM(2007)697, COM(2007)698, COM(2007)699, SEC(2007)1473\} at http://www.ec.europa.eu/information_society/policy/ecomm/doc/library/proposals/ia_en.pdf
} 


\section{Bibliography}

Anderson R (2001) " Why information security is hard - an economic perspective" Computer Security Applications Conference, 2001. ACSAC 2001. Proceedings 17th Annual: 358- 365

Armstrong, M. (2006) Competition in Two-Sided Markets. Rand Journal of Economics Vol. 37, No. 3, Autumn 2006 pp. 668-691

Atkinson, Robert D. and Weiser, Phil (2006) May 30, "A 'Third Way' on Network Neutrality" Available at SSRN: http://ssrn.com/abstract=1004522

Baumol, William J., Cave, Martin E., Cramton, Peter C., Hahn, Robert W., Hazlett, Thomas W., Joskow, Paul L., Kahn, Alfred E., Litan, Robert E., Mayo, John W., Messerlin, Patrick A.A., Owen, Bruce M., Pindyck, Robert S., Smith, Vernon, Wallsten, Scott J., Waverman, Leonard and Lawrence J. White (2007) "Economists' Statement on Network Neutrality Policy" (March). AEI-Brookings Joint Center Working Paper No. RP07-08.

Blythe, Stephen E. (2005) The Regulation of Voice-Over-Internet-Protocol in the United States, the European Union, and the United Kingdom, J. High Tech. L. 5: 161.

Boiteux M. (1956): "Sur la Gestion des Monopoles Publics Astreints B 1' qui libre Budgttaire" Econometrica, 24, 22-44; English translation: "On the Management of Public Monopolies Subject to Budgetary Constraints, Journal of Economic Theory, 3 (19711, 219240.

Botterman, Anderson, van Binst, Cave, Libicki, Ligtvoet, te Velde, de Vries (2003) Enabling the Information Society by Stimulating the Creation of a Broadband Environment in Europe: Analyses of Evolution Scenarios for Future Networking Technologies and Networks in Europe, DG Information Society (MR-1579). Santa Monica: RAND.

Brigham, B. and M. Waterson (2003) "Strategic change in the market for domestic electricity in the UK" Centre for the study of management under regulation working paper. http://users.wbs.warwick.ac.uk/cms_attachment_handler.cfm?f=c9dd7acd-1396-4895-a8c6$\mathrm{f} 485 \mathrm{f} 1 \mathrm{db} 344 \mathrm{f} \& \mathrm{t}=$ strategic_change.pdf

Broadband Stakeholder Group (2006) "Predicting UK Future Residential Bandwidth Requirements." http://www.broadbanduk.org/component/option,com_docman/task,doc_download/Itemid,9/gi d,45/

Brown, I. (2007) "Internet censorship: be careful what you ask for." Proc. International Conference on Communication, Mass Media and Culture, Istanbul, October 2006.

Brown, I., Edwards L. and C. Marsden (2006) "Legal and institutional responses to Denial of Service Attacks." Communications Research Network/Department for Trade and Industry joint seminar on $\quad$ Spam/DDoS, $13 \quad$ November. http://www.communicationsresearch.net/events/article/default.aspx?objid=1464

Businessweek, Online Extra (November 7, 2005) "At SBC, It's All About 'Scale and Scope'” at

http://www.businessweek.com/@@n34h*IUQu7KtOwgA/magazine/content/05_45/b3958092 .htm

Cannon, Robert (2003) The Legacy of the Federal Communications Commission's Computer Inquiries, Fed. Comm. L.J. 55: 167.

Cartwright, S.D. and R.W. Oliver (2000) Untangling the Value Web, Journal of Business Strategy 21(1): 22-7. 
Chen, M.K. and Nalebuff, B. (2006) "One-way essential complements." Yale Working Papers on Economic Applications Discussion Paper Number 22 at http://www.econ.yale.edu/ddp/2006/ddp0022.pdf

Cheng, H., Bandyopadhyay, S. and S. Guo (2007) The Debate on Net Neutrality: A Policy Perspective. http://ssrn.com/abstract=959944.

Cherry, Barbara A. (2006) Misusing Network Neutrality to Eliminate Common Carriage Threatens Free Speech and the Postal System, N. KY. L. Rev. 33: 483

Clark, David (2006) "Net neutrality" Keynote speech, Telecommunications Policy Research Conference, GMU Law School, Alexandira, Virgina. 28 September.

Clark, David (28 February 2007) "The end-to-end argument in today's world: Do we have to destroy the principle to save it?" http://www.communicationsresearch.net/events/article/default.aspx?objid=1835

Clarke, D. (2005) "FIND and Architecture: A new NSF initiative", at http://find.isi.edu/presentation_files/Clark_Arch_Security.pdf

Clayton, R. (2005) "Failures in a Hybrid Content Blocking System." Proc. 5th Workshop on Privacy Enhancing Technologies, Dubrovnik, May 2005, from http://www.cl.cam.ac.uk/ rnc1/cleanfeed.pdf

Clayton, R., Murdoch, S.J. and Watson, R.N.M. (2006) 'Ignoring the Great Firewall of China', paper presented to the Sixth Workshop on Privacy Enhancing Technologies, Cambridge, UK, 28 June, at: http://www.cl.cam.ac.uk/ rnc1/ignoring.pdf

Code Monkey Ramblings Blog (2006) “Network Neutrality”, posted May 20, 2006. http://www.codemonkeyramblings.com/2006/05/network_neutrality.php

Communications Assistance for Law Enforcement Act and Broadband Access and Services, 20 FCC Rcd. 14,989 (2005), on partial reconsideration, 21 FCC Rcd. 5008 (2006).

Communications Research Network (2006) Royal Society workshop on Net Neutrality. http://www.communicationsresearch.net/events/article/default.aspx?objid=8

Communications, Consumer's Choice, and Broadband Deployment Act of 2006. http://thomas.loc.gov/cgi-bin/bdquery/z?d109:SN02686: @ @ @L\&summ2=m\&

Cornes, Richard and Todd Sandler (1996) The Theory of Externalities, Public Goods, and Club Goods Cambridge: Cambridge University Press

Crowcroft, Jon (2007) Net Neutrality: the technical side of the debate. A white paper, 37

ACM SIGCOMM Computer Communication Review 1, at $49-56$. http://portal.acm.org/citation.cfm?id=1198255.1198263\&coll=ACM\&dl=ACM\&idx=J101\&p art $=$ newsletter $\&$ WantType $=$ Journals\&title $=$ ACM $\% 20$ SIGCOMM $\% 20$ Computer $\% 20$ Commu nication\%20Review \&CFID $=15151515 \&$ CFTOKEN $=6184618$

Del Bianco, Mark C. (2006) Voices Past: The Present and Future of VOIP Regulation, COMLCON 14: 365.

Deweerd, H.A. (1973) A Conceptual Approach to Scenario Construction, P-5087, The RAND Corporation.

DuFour, R. Alex (2005) Voice Over Internet Protocol: Ending Uncertainty and Promoting Innovation Through a Regulatory Framework, COMLCON 13: 471

Economides, N. (2007) "Net neutrality, Non-Discrimination and Digital Distribution of Content Through the Internet". http://www.stern.nyu.edu/networks/Economides_Net_Neutrality.pdf

Ellig, Jerry and Alastair Walling (2006) Regulatory Status of VOIP in the Post-Brand X World, 23 SANTA CLARA, COMPUTER \& HIGH TECH. L.J. 89. 
European Commission (2006) 'Staff Working Document', 28 June. http://ec.europa.eu/comm/avpolicy/reg/tvwf/modernisation/consultation_2005/index_en.htm, at section 6.4, Net Neutrality

European Commission (2007) Proposal for a Directive Of The European Parliament And Of The Council amending Directive 2002/22/EC on universal service and users' rights relating to electronic communications networks, Directive 2002/58/EC concerning the processing of personal data and the protection of privacy in the electronic communications sector and Regulation (EC) No 2006/2004 on consumer protection cooperation

European Regulators Group (2007) 07(01) Working Programme for 2007. http://erg.eu.int/doc/work_progr_2007/erg_07_01_work_programme_2007.pdf at p7

FCC Adopts Rules to Ensure Reasonable Franchising Process for New Video Market Entrants,

FCC (2005) Public Notice, FCC Adopts Policy Statement (Aug. 5). http://hraunfoss.fcc.gov/edocs_public/attachmatch/DOC-260435A1.doc

Felten, Edward W. (December 2006) Nuts And Bolts Of Network Neutrality, Practising Law Institute, 24th Annual Institute on Telecommunications Policy \& Regulation, PLI/PAT 887 (317): 326.

Ford, G., T. Kowtsky and L. Spiwak (2006) "Network Neutrality and Industry Structure" Phoenix Center Policy Paper Number 24.

Frieden, Rob (2006) Internet 3.0: Identifying Problems and Solutions to the Network Neutrality Debate.

at http://papers.ssrn.com/sol3/papers.cfm?abstract_id=962181>http://papers.ssrn.com/sol3/paper

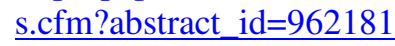

Frischmann, Brett and Barbara van Schewick (forthcoming 2007) Yoo's Frame and What It Ignores: Network Neutrality and the Economics of an Information Superhighway, Jurimetrics J. 47.

Gifford, Raymond L. (June 2006) The Internet Left Gets a Case of the Vapors, The Progress \& Freedom Foundation, Progress Snapshot, Rel. 2.15. http://www.pff.org/issuespubs/ps/2006/ps_2.15_intenet_left.pdf.

Goldsmith, Jack and Tim Wu (2006) Who Controls the Internet? Illusions of a Borderless World, Oxford University Press, Oxford

Goolsbee, A. (2006) The Value of Broadband and the Deadweight Loss of Taxing New Technology, Contributions to Economic Analysis \& Policy 5(1).

Greenberg, Tony and Alex Veytsel (November 2006) "Every Time You Vote against Net Neutrality, Your ISP Kills a Night Elf” at http://www.ramprate.com/marketcommentary/neutrality.html

Greenstein, S. (2006) "Four nightmares for Net Neutrality," IEEE Micro, 26 (6): 12-13, Nov/Dec.

Hahn, R. and R. Litan. 2006. "The Myth of Network Neutrality and What We Should Do About It", AEI-Brookings Joint Center Working Paper No. RP06-33.

Hahn, Robert and Scott Wallsten (2006) "The Economics of Net Neutrality" (Washington, DC: AEI Brookings Joint Center for Regulatory Studies, April 2006). www.aeibrookings.org/publications/abstract.php?pid=1067

Hass, D. (2007) The Never-Was-Neutral Net and Why Informed End Users Can End the Net Neutrality Debates Berkeley Technology Law Journal, 22 (4) 2007.

Hermann, B. (2007) Opening Bottlenecks: On Behalf of Mandated Network Neutrality, Federal Communications Law Journal 59 (1). 
Hogendorn, C. (2006) "Broadband Internet: Net Neutrality versus Open Access" CNIWorking Paper No. 2006-09.

Horlings, Botterman, Cave, Ligtvoet, de Vries (2002) Accelerated Broadband Roll-Out for the Netherlands: A Review of Economic Benefits, Directoraat Generaal Telecommunicatie en Post (MR-1654-NDGTP; September. Santa Monica: RAND).

Impact Assessment (2007) Commission Staff Working Document Impact Assessment Accompanying document to the Commission proposal for a Directive of the European Parliament and the Council amending European Parliament and Council Directives 2002/19/EC, 2002/20/EC and 202/21/EC Commission proposal for a Directive of the European Parliament and the Council amending European Parliament and Council Directives 2002/22/EC and 2002/58/EC Commission proposal for a Regulation of the European Parliament and the Council establishing the European Electronic Communications Markets Authority $\{\operatorname{COM}(2007) 697, \operatorname{COM}(2007) 698, \operatorname{COM}(2007) 699, \quad \operatorname{SEC}(2007) 1473\}$ at http://www.ec.europa.eu/information_society/policy/ecomm/doc/library/proposals/ia_en.pdf

International Telecommunication Union (2006) Strategy and Policy Unit Newslog. ITU $\begin{array}{lllll}\text { Broadband Statistics } & \text { for } & 1 & \text { January }\end{array}$ http://www.itu.int/osg/spu/newslog/CategoryView,category,Broadband.aspx

International Telecommunication Union (March 23-24 2006) What Rules for IP-enabled NGN?, Workshop available at: http://www.itu.int/osg/spu/ngn/event-march-2006.phtml

International Telecommunication Union (Jan. 2007) The Future of Voice: Consumer Issues, Briefing Paper http://www.itu.int/osg/spu/ni/voice/papers/FoV-Ewan-Sutherland-Final.pdf; see also, International Telecommunication Union, The Future of Voice Workshop web site; available at: http://www.itu.int/osg/spu/ni/voice/meeting.phtml

Internet2 Network, World Wide Web site. http://www.Internet2.edu/network/

IP-Enabled Services, WC Docket No. 04-36, E911 Requirements for IP-Enabled ISPs, WC Docket No. 05-196, First Report and Order and Notice of Proposed Rulemaking, 20 FCC Rcd. 10245 (2005).

Kahn and Weiner (1967) The Year 2000: A Framework for Speculation on the Next Thirty Years. MacMillan,.

Kahn, Brown, and Martel (1976) The Next 200 Years: A Scenario for America and the World, New York: William Morrow and Company.

Katz. M. and C. Shapiro (1994) "Systems Competition and Network Effects" The Journal of Economic Perspectives, Vol. 8, No. 2. (Spring, 1994), pp. 93-115.

Kiedrowski, Tom (February 2007) Net Neutrality: Ofcom's view. http://www.wwww.radioauthority.org.uk/media/speeches/2007/02/net_neutrality

Laffont, Jean-Jacques, Scott, Marcus, Patrick, Rey and Jean Tirole (May, 2001) Interconnection and Access in Telecom and the Internet, Amer. Econ. Rev., 91 (2): 287-91.

Laxton (2007) "The end of Net Neutrality" 15 Duke L. \& Tech. J. http://www.law.duke.edu/journals/dltr/articles/pdf/2006DLTR0015.pdf

Lehr, W.S., Gillett, M., Sirbu and J. Peha (2006) "Scenarios for the Network Neutrality Arms Race" Presented at the 34th Research Conference on Communication, Information, and Internet Policy (TPRC).

Leiner, Barry M., Cerf, Vinton G., Clark, David D., Kahn, Robert E., Kleinrock, Leonard, Lynch, Daniel C., Postel, Jon, Roberts, Larry G. and Stephen Wolff. A Brief History of the Internet, Internet Society. http://www.isoc.org/Internet/history/brief.shtml.

Leisinger, Amy L. Spring, (2006) If It Looks Like a Duck: The Need for Regulatory Parity in VOIP Telephony, Washburn L.J. 45: 585. 
Lemley, Mark A. and Lawrence Lessig (2001) The End of End-to-End: Preserving the Architecture of the Internet in the Broadband Era, UCLA L. REV. 48: 925.

T. Lenard and R. May (eds.)(2006) Net Neutrality or Net Neutering: Should Broadband Internet Services be Regulated, Springer http://www.pff.org/issuespubs/pops/pop13.26 net_neutrality transcript.pdf

Litan, R. and H. Singer (2007) "Unintended Consequences of Net Neutrality Regulation" forthcoming Journal on Telecommunications \& High Technology Law.

Madison River Communications, LLC, Order, DA 05-543, 20 FCC Rcd 4295 (2005). http://hraunfoss.fcc.gov/edocs_public/attachmatch/DA-05-543A1.pdf.

Marcus, Scott (July, 2002) The Potential Relevance to the United States of the European Union's Newly Adopted Regulatory Framework for Telecommunications, Federal Communications Commission, Office of Plans and Policy Working Paper Series No. 36. http://www.fcc.gov/osp/workingp.html

Marsden, C., Cave, J., Nason, E., Parkinson, A., Blackman C. and Rutter, J. (2006) Assessing Indirect Impacts of the EC Proposals for Video Regulation, TR-414 for Ofcom. Santa Monica: RAND.

Martin, Kevin J. Dec. 29, 2006. Joint Statement of Chairman and Commissioner Deborah Taylor Tate AT\&T BellSouth Merger Approval. http://hraunfoss.fcc.gov/edocs_public/attachmatch/DOC-269275A2.doc

McTaggart, Craig (Dec. 21, 2002) A Layered Approach to Internet Legal Analysis http://www.innovationlaw.org/cm/ilg2002/reading/layered1.pdf

McTaggart, Craig. (Sep. 30, 2006) Was The Internet Ever Neutral?, paper presented at the 34th Research Conference on Communication, Information and Internet Policy, George Mason University School of Law, Arlington, Virginia. http://web.si.umich.edu/tprc/papers/2006/593/mctaggart-tprc06rev.pdf.

Meinrath, S. and V. Pickard (2007) "The New Network Neutrality: Criteria for Internet Freedom".

http://web.si.umich.edu/tprc/papers/2006/614/The\%20New\%20Network\%20Neutrality\%20v 4.4.pdf

Meyer, David (2007) The Perfect Storm (regarding ISPs, telcos and content charging/provisioning). http://www.1-4-5.net/ dmm/talks/apricot2007/perfect_storm

National Cable \& Telecommunications Association v. Brand X Internet Services (2005)., 125 S. Ct. 2688

Odlyzko, Andrew and David Levinson (2007) Too expensive to meter: The influence of transaction costs in transportation and communication. http://www.dtc.umn.edu/ odlyzko/doc/metering-expensive.pdf

Odlyzko, A. (2000) Presentation to CITI conference on Internet and TV. http://www.dtc.umn.edu/ odlyzko/doc/tv.Internet.pdf

Odlyzko, A. (2006) "Internet traffic growth: Sources and implications." http://www.dtc.umn.edu/ odlyzko/doc/itcom.Internet.growth.pdf

OECD (2006) Multiple Play: Pricing and Policy Trends, Directorate for Science, Technology and Industry, Committee for Information, Computer and Communications Policy, Working Party on Telecommunication and Information Services Policies DSTI/ICCP/TISP(2005)12/FINAL 24 (April 7, 2006).

OECD (April 2007) "Internet Traffic Prioritisation", OECD, Paris

Ofcom (2007) A new approach to public service content in the digital age: Responses to the discussion document on the potential role of the Public Service Publisher, at 
http://www.ofcom.org.uk/consult/condocs/pspnewapproach/summary responses/summary.pd $\underline{\mathrm{f}}$

Orlowski, Andrew (2007) Net Neutrality, a monkey hangers guide, The Register. http://www.theregister.co.uk/2007/03/21/net_neutrality_a_monkey_hangers_guide/

Owen, B. (2007) "The Net Neutrality Debate: Twenty-Five Years after United States v. AT\&T and 120 Years after the Act to Regulate Commerce".

Owen, B. and Rosston (2002) "Local Broadband Access: Primum Non Nocere or Primum Processi? A Property Rights Approach" Stanford Institute For Economic Policy Research working paper 02-37. in T. Lenard and R. May (eds.) Net Neutrality or Net Neutering: Should Broadband Internet Services be Regulated, Springer.

Pfleeger, Charles and Pfleeger, Shari L. (2006) Security in Computing, $4^{\text {th }}$ Edn, Prentice Hall Pearson.

Quinn, Jr., Robert W., (2006) Sr. Vice President Federal Regulatory AT\&T letter to Ms. Marlene H. Dortch, FCC Secretary; attached to Federal Communications New Release, FCC (rel. Dec. 29, 2006) Approves Merger Of AT\&T Inc. and BellSouth Corporation--Significant Public Interest Benefits Likely to Result. http://hraunfoss.fcc.gov/edocs_public/attachmatch/DOC-269275A1.pdf

Ralph, E. (2006) "Letter: Comment on the Economics of Net Neutrality" Economists Voice October.

Ramsey, F. P. (1927): "A Contribution to the Theory of Taxation," Economic Journal, 37, 4761.

Robinson, Joan, (1933) The Economics of Imperfect Competition, London: Macmillan.

Rochet, Jean-Charles and Jean Tirole, Two-Sided Markets: An Overview (March 12, 2004). http://faculty.haas.berkeley.edu/hermalin/rochet tirole.pdf.

Rosen, S. (1981) "The Economics of Superstars" The American Economic Review 71(5): 845858

Rothschild, M. and J. Stiglitz (1976) "Equilibrium in competitive insurance markets: An essay on the economics of imperfect information" Quarterly Journal of Economics 90: 62949.

Roycroft, T. (2006) "Economic Analysis And Network Neutrality: Separating Empirical Facts From Theoretical Fiction." http://nsawatch.org/images/asset_upload_file322_26830.pdf

Roycroft, Trevor R. (June 2006) Economic Analysis and Network Neutrality: Separating Empirical Facts From Theoretical Fiction. http://www.freepress.net/docs/roycroft_study.pdf

Schewick, B. van (2005) "Towards an Economic Framework for Network Neutrality Regulation" paper for $33^{\text {rd }}$ Telecoms Policy Research Conference 2005.

Schewick, Barbara van (forthcoming 2007) Towards an Economic Framework for Network Neutrality Regulation, Journal on Telecommunications \& High Technology Law 5.

Scott, Dougal (2007) Speech at Westminster eForum. http://www.wwww.radioauthority.org.uk/media/speeches/2007/03/regulate

Shapiro, C. and H. Varian (1998) "Information rules : a strategic guide to the network economy", Boston: Harvard University Press.

Sidak, J. Gregory (2006) A Consumer-Welfare Approach to Network Neutrality Regulation of the Internet, Journal of Competition Law \&Economics 2 (3): 349.

Sidak, J. Gregory (Feb. 7, 2006) Testimony of, United States Senate, Committee on Commerce, Science and Transportation. http://commerce.senate.gov/pdf/sidak-020706.pdf 
Sirbu, M. (2007) "What is the Network Neutrality debate about?" presentation at conference A Workshop on Network Neutrality: American and European Perspectives, Paris, 29 May 2007.

Smith, R.M. (1964) Some Thoughts on Scenarios, D-12250-PR, The RAND Corporation,

Spence, M. (1978) "Product differentiation and performance in insurance markets" Journal of Public Economics 10: 427-47.

Tapscott, D., Ticoll, D. and Lowy, D. (2000) Digital Capital: Harnessing the Power of Business Webs. Boston. MA: Harvard Business School Press.

Telecommunications Act 1996, P.L. 104-104, 110 Stat. 56 (1996), Sec. 734(c) (2006), codified at 47 U.S.C. $\$ 332(\mathrm{c})(7)$.

Thierer, A. (2004) "Net Neutrality: Digital Discrimination or Regulatory Gamesmanship in Cyberspace?" Policy Analysis 507.

Thierer, Adam (2005) Are 'Dumb Pipe' Mandates Smart Public Policy? Vertical Integration, Net Neutrality, and the Network Layers Model, Journal on Telecommunications \& High Technology Law 3: 275.

Trope, Konrad L. (December 2005) Voice Over Internet Protocol: The Revolution in America's Telecommunications Infrastructure, Comp. \& Internet L. 22 (1): 12, 1,4.

United States House of Representatives (March 30, 2006) Committee on Energy and Commerce, Subcommittee on Telecommunications and the Internet, Committee Print on the Communications Opportunity, Promotion, and Enhancement Act of 2006. http://energycommerce.house.gov/reparchives/108/Hearings/03302006hearing1823/hearing.ht $\underline{\mathrm{m}}$

Cerf, V. (2007) United States Senate Committee on Commerce, Science and Transportation, Prepared Statement of Vinton G. Cerf, Vice President and Chief Internet Evangelist, Google, Inc. http://commerce.senate.gov/hearings/testimony.cfm?id=1705\&wit_id=4958

United States Senate (Feb. 7 2006) Committee on Science, Commerce and Transportation, Net Neutrality, Full Committee Hearing, http://commerce.senate.gov/hearings/witnesslist.cfm?id=1705

Van Der Berg, R. (2007) "Developments In Fibre Technologies And Investment”, OECD draft, DSTI/ICCP/CISP(2007)4, of 3 May, OECD, Paris

Waldfogel, J. and J. Wulf (2006) Measuring the Effect of Multimarket Contact on Competition: Evidence from Mergers Following Radio Broadcast Ownership Deregulation, Contributions to Economic Analysis \& Policy 5(1)

Weiser, Phillip J. (2002) Law and Information Platforms, Journal on Telecommunications \& High Technology Law 1.

Werbach, Kevin (2002) A Layers Model for Internet Policy, Journal on Telecommunications \& High Technology Law 1 (37).

Wirtz, B.W. (2001) Reconfiguration of Value Chains in Converging Media and Communications Markets, Long Range Planning 34: 489-506.

Woroch, G. (2004) Open Access Rules and Equilibrium Broadband Deployment, in Frontiers of Broadband, Electronic and Mobile Commerce, edited by Cooper and Madden. Springer.

Wu, T. (2003) Network Neutrality and Broadband Discrimination, J. TELECOM \& HIGH TECH L. 2: at p. 141

Wu, T. (2004) The Broadband Debate: A User's Guide, J. TELECOM \& HIGH TECH L.

Yanellis, D. (2006) “On access pricing with network externalities" Atlantic Economic Journal 30 (2): 186-90. 
Yoo, Christopher S. (2004) Would Mandating Broadband Network Neutrality Help or Hurt Competition? A Comment on the End-to-End Debate, Journal on Telecommunications \& High Technology Law 3: 23.

Yoo, Christopher S. (2005) "Beyond Network Neutrality" Harvard Journal of Law \& Technology 19 (1).

Yoo, Christopher S. (2006) "Network Neutrality and the Economics of Congestion". http://lgst.wharton.upenn.edu/cmcl/Documents/Yoo.pdf 94 GEO. L.J. 1847

Zittrain, J. and Edelman, B. (2003) Internet Filtering in China, Los Alamitos, CA : IEEE Computer Society Publications Office, 2003 